\title{
Facile Ultrasonic Synthesis of Zirconium Based Porphyrinic MOFs for Enhanced Adsorption Performance Towards Anionic and Mixed Dye Solutions
}

\author{
Roya Hariri $^{1} \cdot \underline{\text { Saeed Dehghanpour }}^{1} \cdot$ Samaneh Sohrabi ${ }^{1}$
}

1 Department of Chemistry, Faculty of Physics and Chemistry, Alzahra University, Tehran, Iran

\begin{abstract}
A porphyrinic mesoporous metal-organic framework (PCN-222(M) $(\mathrm{M}=\mathrm{Mn}, \mathrm{Fe}, \mathrm{Cu}))$ has been synthesized by a simple sonochemical preparation method without high temperature in a short period of time. The ultrasonic method for the preparation of PCN222(M) was found to be an efficient procedure with a good quantitative yield (PCN222(M)-U). Harmful cationic and anionic dyes have been removed from wastewater using PCN-222(M). The comparative study of the influences of metalloporphyrin and non-metal porphyrin frameworks (PCN-222) on the adsorption process has been performed. Remarkably high adsorption capacity over PCN-222(M) for the anionic dyes is reported. The porphyrinic metal center of frameworks and $\mathrm{pH}$ values affected dye adsorption capacity, indicating the effective role of electrostatic interactions on dye adsorption. Due to the aggregation of $\mathrm{MB}$ and $\mathrm{MO}$, a significant increase in the adsorption capacity was observed in a mixture of MB-MO solution at $\mathrm{pH}$. High adsorption capacity over PCN-222(M) has been estimated using Langmuir and Freundlich equations. The adsorption kinetics, thermodynamic parameters, stability and reusability of adsorbents have also been reported. The stability of PCN-222(M) in water over three months was investigated (PCN-222(M)-3).
\end{abstract}

Keywords: $\mathrm{MOF} \cdot \mathrm{PCN}-222(\mathrm{M})(\mathrm{M}=\mathrm{Mn}, \mathrm{Fe}, \mathrm{Cu}) \cdot$ Metalloporphyrin $\cdot$ Ultrasound synthesis · Dye adsorption · Adsorption isotherms.

Link: https://link.springer.com/article/10.1007/s10904-020-01704-5 